\title{
Suggestion Regarding Support for Continued Employment of Foreign Healthcare Personnel Coming to Japan under the Economic Partnership Agreement
}

\author{
Fumiko Sato
}

Department of Nursing, Senri Kinran University, Fujishirodai, Suita, Osaka 565-0873, Japan

\author{
Article Details \\ Article Type: Commentary Article \\ Received date: $25^{\text {th }}$ February, 2019 \\ Accepted date: $26^{\text {th }}$ March, 2019 \\ Published date: $29^{\text {th }}$ March, 2019
}

"Corresponding Author: Fumiko Sato, Department of Nursing, Senri Kinran University, Fujishirodai, Suita, Osaka 5650873, Japan. E-mail: f-sato@.cs.kinran.ac.jp

Citation: Sato F (2019) Suggestion Regarding Support for Continued Employment of Foreign Healthcare Personnel Coming to Japan under the Economic Partnership Agreement. J Comp Nurs Res Care 4: 139. https://doi.org/10.33790/jcnrc1100139.

Copyright: (C2019, This is an open-access article distributed under the terms of the Creative Commons Attribution License 4.0, which permits unrestricted use, distribution, and reproduction in any medium, provided the original author and source are credited.

Since the mid-1990s, there has been a rapid increase in the international movements of medical and healthcare workers, primarily doctors and nurses. In addition to the general acceleration of movement across borders as a result of globalization, the declining birth rates and aging populations in developed countries have increased the demand for workers in the medical, nursing, and nursing-care fields [1]. International movement of healthcare workers is primarily from countries in Asia and Africa to Europe, North America, and East Asia [1]. Japan is not an exception. Japan started receiving nurse and care worker candidates from Indonesia in August 2008 under the Economic Partnership Agreement (EPA) that came into effect in July of that year. Subsequently, EPA candidates began to arrive in Japan from the Philippines and Vietnam in the following years, and this trend has strengthened the international movement of workers in the medical and nursing fields in Japan. Under the EPA, foreigners who meet certain application requirements come to Japan as "nurse candidates" or "care worker candidates," and these candidates receive training at a hospital or caregiving facility in Japan; they sign a contract of employment before arriving [2]. They aim to pass the Japanese national exam and obtain Japanese national qualifications during their respective periods (a maximum of three years for nurse candidates and four years for care worker candidates) [2]. However, their national exam pass rate has remained much lower than the rate for all examinees; $17.7 \%$ for nurses (FY 2017), and $50.7 \%$ for care workers (FY 2017). The pass rate for all candidates for FY 2017 for nurses was $91.0 \%$ and $70.8 \%$ for care workers [3-5]. Quite a few candidates gave up and returned to their home countries. Moreover, $20 \%$ of the EPA candidates who passed the national qualification returned to their home countries even though that they can remain in Japan as nurses or care givers without restriction after obtaining national certification [6]. The major reasons for their repatriation were personal ones such as care for aged parents, marriage and so on.On the other hand, frustration with difficulties in communicating in Japanese and adjusting to a working environment that requires strict commitment to rules and long working hours were also reported [6].

For EPA candidates, living and working in Japan - a country with a culture likely to be very different from their home culture - may be an additional source of stress. Cultural differences including lifestyle, language, climate and other environmental changes such as overseas migration are often felt as a big strain for those from different cultures [7]. Daily experience leads to accumulation of mental and physical fatigue, and if left unaddressed, this can lead to physical and mental health disorders [7]. In fact, psychiatric problems are increasing among foreigners living in Japan [8]. One report indicated that there were some mental problems in 16 people $(22.5 \%)$ in a mental health survey of 71 Indonesian nurses and nursing care worker candidates who came to Japan under the EPA program [9]. In addition to routine stresses, they are considered to be under additional stress because they are engaged in a labor environment and do manual tasks accompanied by a sense of responsibility and tension particular to medical and nursing care workplaces. In addition, the survey results revealed that the "acquisition state of national qualifications (acquired)" was a negative factor for their mental health [9]. Based on the EPA program, nurse and care worker candidates change from supplementary work as a candidate to a professional job as qualified health care personnel after passing the national examination [2]. It is inferred that there is a negative impact on their mental health with more tasks and responsibilities than before [9].

According to the Japan International Corporation of Welfare Services, training at facilities that accept nurse and care worker candidates is established under certain conditions, with provision of appropriate training to prepare for national examinations, assignment of training managers, and provision of learning support for specialized knowledge and skills [10]. Additionally, assistance with ongoing study of Japanese and support in adapting to the workplace and lifestyle habits in Japan are needed [10]. However, there is no uniform national policy regarding the contents of these training programs [11]. Instead, each individual facility accepting foreign candidates is entrusted to provide appropriate support. Moreover, since the cost of training is a burden on the facility, conditions and performance in implementation between facilities are considerably different $[11,12]$. In the framework of the EPA program, due to the number of candidates taking national exams and the length of stay being severely limited, EPA candidates and faculty's greatest concern has become national exam measures [13]. It is easy to imagine that other support is inadequate. Even at the policy level, the primary effort is directed at helping candidates to pass the national 
examination [11]; there is no mention of support for those candidates who succeed in passing the examination. Even if they pass the national exam and start working as a qualified nurse or care worker, they still need support based on individual abilities and needs. After all the support aimed at passing exams, further continuous support with medium- and long-term perspectives is needed so that they can gradually adjust to new tasks and roles. Also, since they are living in Japan, continuous support in terms of lifestyle, including intercultural adaptation and acquisition of Japanese language, is essential.

It has been 11 years since the acceptance of foreign candidates by the EPA; however, there is little public knowledge regarding the conditions of specific support provided by the various facilities that accept such candidates in Japan. Tukazaki introduced a support program at one medical facility, at which the director set up measures to support foreign nurses to pass the national examination as a top priority at their facility. Then, after passing the examination, nurses undergo level-up practical training in all areas of the wardwith an assigned preceptor [14]. This approach was originally developed by this particular facility, which has been accepting foreign candidates prior to the start of the EPA program, andit now has extensive experience in training and developing foreign staff [14]. To widely disseminate the efforts of these experienced facilities to the public and other facilities would contribute to an improvement in the support systems of participating facilities nation wide. It would be helpful to promote a change from a narrow focus on support for exam success to a support program focusing on continuing employment.

Japan is expected to face an unprecedented aging society in the near future, and the number of elderly who will need medical and nursing care over the long term will increase. As a major factor to meet the predicted medical and nursing care needs, it is essential to ensure there are enough health care personnel and support foreign workers to settle in to their workplaces. While securing human resources within the country is difficult, the flow of healthcare workers from overseas has become very important in delivering services at hospitals and care giving facilities in Japan. In order to secure foreign healthcare personnel, it is vital to develop an attractive work environment and an effective support program for candidates so that they will choose Japan as a work destination.

\section{References}

1. Sato C (2009) International migration of nurses and the health human resources policy - a case of South Africa. Ritsumeikan International Affairs 29: 13-32.

2. Ministry of Health, Labour and Welfare (2018) Acceptance of Indonesian nurse and care worker candidates. From Indonesia, Philippine, and Vietnam.

3. Ministry of Health, Labour and Welfare (2018) Result of national nursing exam of EPA Foreign candidates (last 10 years).

4. Ministry of Health, Labour and Welfare (2018) Result of the 30th national exam of EPA care worker candidates.

5. Ichigen $\mathrm{T}$ (2019) Learning Haiku aiming to work as a care worker in Japan. Yomiuri Shinbun dated on 5th of February.

6. Ikeda K (2014) 2 out of 10 foreign nurses and care workers return to their home countries. Yomiuri Shinbun dated on 27nd of June.

7. Ishikawa T, Takahashi S (1993) Cultural stress and psychosomatic symptoms. Heart Science 49: 75-79.

8. Oonishi M (2003) Mental health of foreign resident in Japan. J Edu Med 51: 79-84.

9. Sato F (2016) Investigation of mental health in Indonesian health workers immigrating to Japan under the Economic Partnership Agreement. Nurs Health Sciences 18: 342-349.
10. Japan international Cooperation of Welfare Service (2019) Pamphlet on acceptance of foreign nurses and care workers based on the 2019 EPA.

11. Nagae M, Iwase T, Furuzawa A, Tsyubonouchi C, Shimai S, et al (2013) Study on the adaptation of EPA-based Indonesian nurse candidates to their workplace environment in Japan. Japanese Red Cross Toyota College of Nursing Bulletin 8: 197-119.

12. Kim M (2010) The training for care worker candidate who come from Indonesia to Japan due to EPA and their perception of the national qualification of care worker. Otsuma Women's University Bulletin of Faculty of Human Relations 12: 37-44.

13. Hatanaka K, Tanaka K (2012) The Research Note about the Background of the Cultural Adaptation Problems of Foreign Nurses and Care Worker Candidates in Japan-From the View of EPA Systems and Its Circumstances. J Humanities Soc Sci 34: 79-90.

14. Tukazaki A (2010) What is the training method for foreign nurses and the merits? Nursing Business 4: 48-52. 